\title{
Incidence of congenital hypothyroidism: retrospective study of neonatal laboratory screening versus clinical symptoms as indicators leading to diagnosis
}

\author{
J ALM, L HAGENFELDT, A LARSSON, K LUNDBERG
}

\begin{abstract}
Filter paper blood samples taken routinely from 100239 newborn infants were radioimmunoassayed five years later for plasma thyrotrophin concentrations. In 32 cases $(0.03 \%)$ these were found to be raised. Thirty one of these children were traced and subjected to follow up examination by a paediatrician and a psychologist.

Of the 31 children, 15 were found to have been receiving treatment for congenital hypothyroidism since a median of 5 months of age (diagnosed group). Of the 16 others, seven children were found to have raised serum thyrotrophin concentrations and were classified as hypothyroid (undiagnosed group). The remaining nine children were euthyroid.

Children in the diagnosed group had a mean Griffiths developmental quotient of 87 (control value $103 ; p<0.01$ ), and five out of 13 showed impaired neurological development. Of the remainder, those in the undiagnosed group had a mean developmental quotient of 100 and those in the euthyroid group a mean developmental quotient of 107.
\end{abstract}

In this study achieving a detection rate of congenital hypothyroidism of one in 3000 in a neonatal screening

\footnotetext{
Department of Paediatrics, St Göran's Children's Hospital, Karolinska Institute, Stockholm

J ALM, MD, paediatrician

Department of Clinical Chemistry, Karolinska Hospital, Stockholm L HAGENFELDT, MD, lecturer and clinical chemist

Department of Paediatrics, University Hospital, Uppsala

A LARSSON, MD, professor of paediatrics

PKU-Section, Department of Bacteriology, National Bacteriological Laboratory, Stockholm

K LUNDBERG, BSC, microbiologist

Correspondence to: Professor A Larsson, Department of Paediatrics, University Hospital, S-751 85 Uppsala, Sweden.
}

programme resulted in overdiagnosis of about a quarter of patients considered to have true positive findings. This was outweighed, however, by the early identification of all infants with the disease.

\section{Introduction}

The incidence of congenital hypothyroidism based on neonatal laboratory screening is greater than the incidence based on clinical signs and symptoms. When patients are diagnosed clinically the incidence has been found to vary between one in 5800 and one in $6900,,^{1-3}$ whereas based on neonatal screening the incidence is between one in 2900 and one in $3600 .{ }^{4} 5$ This discrepancy may be due to the fact that some children with the disorder go undetected when general laboratory screening is not utilised. On the other hand, neonatal laboratory screening will detect some children with minor disturbances of thyroid function which are clinically insignificant. In order to clarify the matter we have taken a random population of 100000 Swedish children and determined the thyrotrophin concentrations in their filter paper blood samples which had been collected in the neonatal period and stored for about five years. Children with raised neonatal values were investigated.

\section{Materials and methods}

In Sweden filter paper blood samples are collected routinely from all newborn infants for screening for phenylketonuria and galactosaemia. ${ }^{6}$ Samples are usually taken when the child is 5 days old and are accepted as valid only if collected after the third day of life. After screening the remainder of each sample is stored at $4{ }^{\circ} \mathrm{C}$. For this study samples from all children born in Sweden during February 1977 to March 1978 were retrieved and those that were sufficient included. These samples were analysed in 1981-2 for thyrotrophin concentrations using a single $6 \mathrm{~mm}$ disc, rabbit antihuman thyrotrophin, and other reagents from MILAB AB (Malmö, Sweden). All blood samples containing more than $40 \mathrm{mU}$ thyrotrophin per litre plasma were reanalysed for the hormone using duplicate samples and the same reagents but a different rabbit antihuman thyrotrophin (Calbiochem, Lucerne, Switzerland). Children whose neonatal 
thyrotrophin concentrations exceeded $40 \mathrm{mU} / 1$ in this second determination were followed up.

Information was collected from registers in maternal health clinics, well baby clinics, and, if applicable, paediatric departments. Each child was examined at $4 \frac{1}{2}$ to $5 \frac{1}{2}$ years of age by one paediatrician and one psychologist, who did not know either the thyrotrophin concentration in the filter paper blood sample or the serum hormone concentrations at the time of follow up.

The investigation included neurological evaluation, ${ }^{78}$ and intellectual development was assessed using the Griffiths test standardised for Swedish children.' Serum samples were analysed in one laboratory using commercial radioimmunoassay kits for thyroxine and triiodothyronine (Pharmos Diagnostica, Turkku, Finland) and thyrotrophin (Diagnostic Products Corporation, Los Angeles, USA). Serum from a healthy control group (26 boys and 11 girls aged 3-8 years) was analysed in parallel. Thyrotrophin releasing hormone tests were performed as described. ${ }^{10}$

The study was approved by the ethical committee of the Karolinska Institute.

Statistical analyses-Neonatal thyrotrophin was compared by frequency analyses ( $\chi^{2}$ test) of values above and below $100 \mathrm{mU} / 1$

TABLE I-Results of thyrotrophin analyses in stored neonatal filter paper blood samples

\begin{tabular}{lr}
\hline & No of children \\
\hline Total population & 100239 \\
Plasma thyrotrophin & 239 \\
>40 mU/1 & 166 \\
Patients with diagnosed congenital rabbit antihuman thyrotrophin & 32 \\
Patients with undiagnosed congenital hypothyroidism & 15 \\
Euthyroid children & 7 \\
Lost to follow up & 9 \\
& 1 \\
\hline
\end{tabular}

plasma. Serum hormone concentrations and developmental quotients were compared using Student's $t$ test, and one tailed probabilities of $<0.05$ were regarded as statistically significant.

\section{Results}

Coverage of retrospective screening for thyrotrophin-During February 1977 to March 1978, 105675 neonatal filter paper blood samples were received at the central screening laboratory. Five years later we obtained 100239 of these which were adequate for analysis. Thus the coverage of retrospective screening for thyrotrophin was $95 \%$.

Thyrotrophin screening-The proportion of filter paper samples containing over $40 \mathrm{mU}$ thyrotrophin per litre plasma, based on single samples and using MILAB rabbit antihuman thyrotrophin, was one in 600 , and this was reduced to one in 3100 after reassay with Calbiochem rabbit antihuman thyrotrophin (table I). Of the 32 children with positive screening test results, 15 had already been diagnosed as congenitally hypothyroid on the basis of clinical signs and symptoms-that is, one in 6700 . In a separate inquiry to all paediatric departments in Sweden these 15 children were found to be the only ones with recognised congenital hypothyroidism born in the screened population. Thus patients with recognised congenital $i$ hypothyroidism had a neonatal thyrotrophin concentration of $\leqslant 40$ \% $\mathrm{mU} / \mathrm{l}$. No mother of a child with a positive screening test result had been treated with antithyroid drugs. Furthermore, there was no report of excessive iodine administration to any mother or infant.

Follow up of children with positive screening test results-Thirty one $\vec{\exists}$ of the 32 children with raised neonatal concentrations of thyrotrophin were traced for follow up at $4 \frac{1}{2}$ to $5 \frac{1}{2}$ years of age (table II). The $\mathrm{O}$ remaining child (neonatal thyrotrophin concentration $43 \mathrm{mU} / 1$ plasma) had emigrated. The Griffiths test was performed in 26 of the 31 children and neurological development tests in 26 . One child (case 27) was excluded from these tests because of Down's syndrome and

TABLE II-Development and serum hormone concentrations at 5 years of age in 31 children with raised thyrotrophin concentrations in the neonatal period (filter paper blood sample)

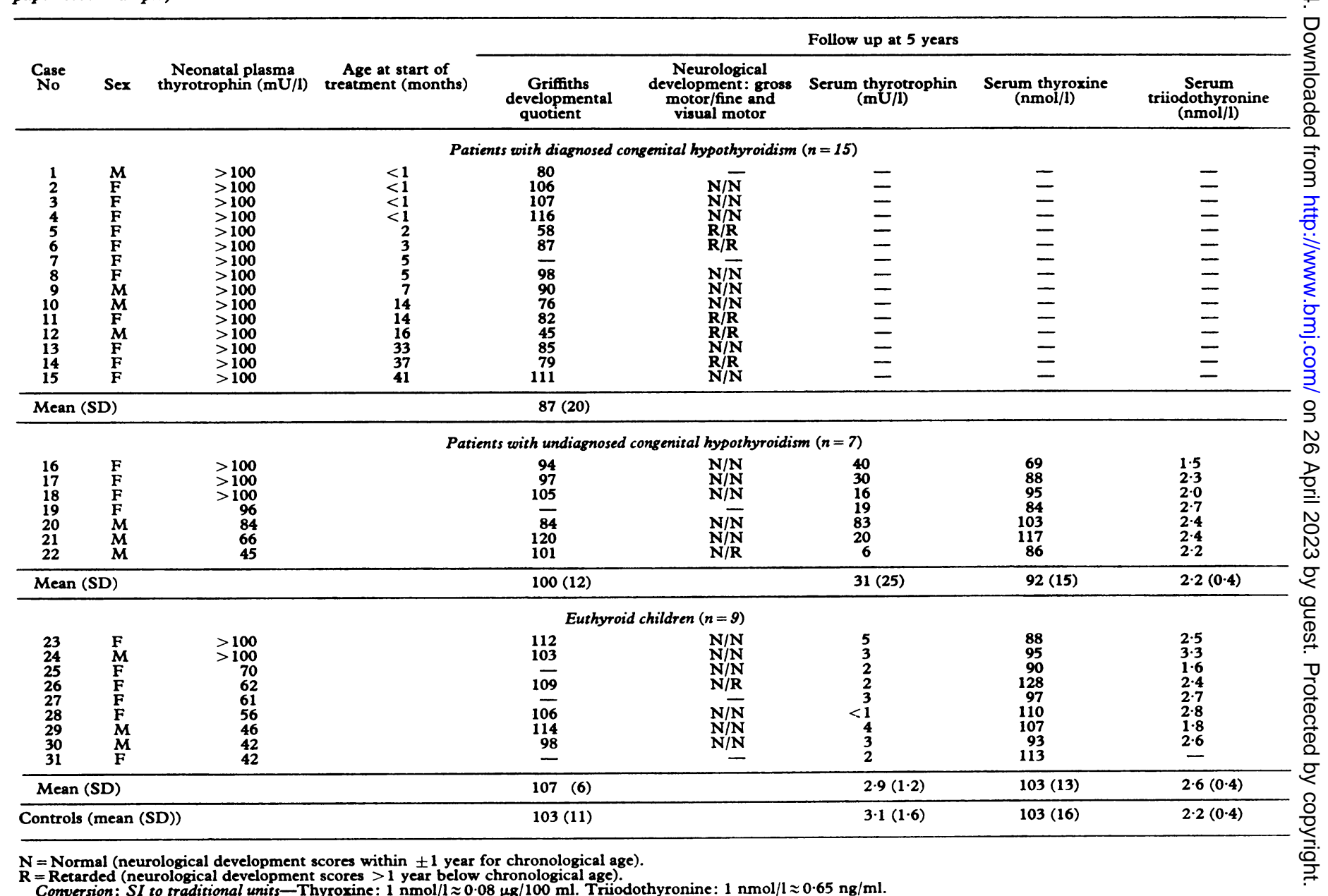


multiple malformations. The last patient (case 31 ) could not be given a formal Griffiths test or be evaluated for neurological development because she had been adopted in Finland. She was reported to have normal psychomotor development. In the remaining children who did not have these tests either the parents or the child refused to cooperate.

\section{PATIENTS WITH DIAGNOSED CONGENITAL HYPOTHYROIDISM}

In the group already receiving treatment for congenital hypothyroidism at the time of follow up (cases 1-15; table II) the neonatal thyrotrophin values were exceptionally high. Despite storage of the filter paper samples for more than four years everyone showed a thyrotrophin value of more than $100 \mathrm{mU} / 1$ plasma. Three of the infants had been delivered by caesarean section, two because of postmaturity and one for maternal psychological reasons. The mean birth weight of the group was $3530 \mathrm{~g}$, and the male to female ratio 4:11. One child had had an Apgar score of less than 7 at five minutes, and another had been given phototherapy for hyperbilirubinaemia. No child was born preterm.

The diagnosis had been established by clinical signs and symptoms in combination with raised thyrotrophin and decreased thyroxine concentrations. All patients were treated with thyroxine. Treatment had started at a median age of 5 months. In six cases treatment had been initiated after the age of 1 year. Records from well baby clinics and paediatric departments showed that clinical signs and symptoms of congenital hypothyroidism had appeared at a median age of 4 months.

Griffiths tests were performed in all but one patient (case 7). The mean developmental quotient was 87 , which was significantly lower than in both a Swedish control population ${ }^{9}(p<0.01)$ and the euthyroid group $(p<0.05)$. Nine out of 14 patients had a developmental quotient below the $-1 \mathrm{SD}$ level (92) and five below the -2 SD level (81).

The children with diagnosed congenital hypothyroidism had lower scores in each of the six developmental scales in the Griffiths test as compared with the other children in the study (table III). The most pronounced differences between the children with diagnosed disease and the euthyroid children were in the motor $(p<0.01)$, visual motor $(p<0.05)$, and performance scales $(p<0.01)$.

TABLE III-Mean developmental quotients in different components of Griffiths test in children with raised thyrotrophin values in neonatal period (filter paper blood sample)

\begin{tabular}{|c|c|c|c|}
\hline \multirow[b]{2}{*}{ Griffiths scale } & \multicolumn{3}{|c|}{ Mean Griffiths developmental quotient (SD) } \\
\hline & $\begin{array}{c}\text { Patients with } \\
\text { diagnosed } \\
\text { congenital } \\
\text { hypothyroidism } \\
(\mathrm{n}=14)\end{array}$ & $\begin{array}{l}\text { Patients with } \\
\text { undiagnosed } \\
\text { congenital } \\
\text { hypothyroidism } \\
(n=6)\end{array}$ & $\begin{array}{c}\text { Euthyroid } \\
\text { children } \\
(n=6)\end{array}$ \\
\hline $\begin{array}{l}\text { A, motor } \\
\text { B, social } \\
\text { C, language } \\
\text { D, visual motor coordination } \\
\text { E, performance } \\
\text { F, logical reasoning }\end{array}$ & $\begin{array}{l}81(22)^{* *} \\
100(21) \\
91(27) \\
89(25)^{*} \\
79(18)^{* *} \\
84(24)\end{array}$ & $\begin{array}{r}97(16)^{*} \\
103(19) \\
113(19) \\
99(8) \\
88(27)^{*} \\
101(18)\end{array}$ & $\begin{array}{l}111(9) \\
112(9) \\
111(19) \\
110(10) \\
108(16) \\
91(5)\end{array}$ \\
\hline Global mean & $87(20)^{*}$ & $100(12)$ & $107(6)$ \\
\hline
\end{tabular}

Compared with euthyroid group $* p<0.05$ and $* * p<0.01$.

The neurological development tests were performed in 13 patients in the diagnosed group. Five of them were found to be retarded by more than one year. One child (case 12) had spastic diplegia and another (case 13) had severe intentional tremor.

\section{PATIENTS WITH UNDIAGNOSED CONGENITAL HYPOTHYROIDISM}

Seven children with raised thyrotrophin values in their neonatal filter paper blood samples were classified as hypothyroid at 5 years of age. Of these, six (cases 16-21) were found to have raised serum thyrotrophin concentrations, and one (case 22) showed a pronounced overshoot of the concentration after stimulation with thyrotrophin releasing hormone (table II). The median neonatal thyrotrophin concentration in this group was $96 \mathrm{mU} / 1$ plasma, and the proportion of values below $100 \mathrm{mU} / \mathrm{l}$ was significantly higher than in the diagnosed group $(p<0.01)$. There was, however, an appreciable overlap between the two groups. Three of the seven patients with undiagnosed disease had thyrotrophin values above $100 \mathrm{mU} / 1$ plasma in their neonatal samples.

Table II gives the serum hormone concentrations found at follow up. In a typical case thyrotrophin was raised in combination with low normal thyroxine and normal triiodothyronine values. The mean thyrotrophin concentration in the undiagnosed group was significantly increased compared with the control value $(p<0.001)$, while the serum thyroxine concentration was decreased $(p<0.05)$.

One child had been delivered by caesarean section because of an estimated gestational age of 43 weeks. All the other children had been delivered vaginally at term. The average birth weight of the group was $3750 \mathrm{~g}$, and the male to female ratio 3:4. No child had had a five minute Apgar score of less than 7 and none was treated for hyperbilirubinaemia.

No child had goitre. In two cases (16 and 18) the child's height was less than $-2 S D$ of the mean for age. The mean Griffiths developmental quotient was 100 and did not differ significantly from the control mean of 103. These children did, however, perform significantly worse than the euthyroid children in the motor and performance scales of the Griffiths test (table III). Neurological development tests were performed in six of the seven children and gave normal results except in one (case 22).

All seven children classified as suffering from undiagnosed congenital hypothyroidism at the age of 5 years were given thyroxine treatment. When last seen four had had a return to normal of their serum thyrotrophin concentrations and had serum thyroxine values within the reference range.

\section{EUTHYROID CHILDREN}

Nine children with raised neonatal thyrotrophin values were classified as euthyroid at follow up (cases $23-31$; table II). In two cases the neonatal value exceeded $100 \mathrm{mU} / \mathrm{l}$ plasma, whereas in the others values ranged from 42 to $70 \mathrm{mU} / \mathrm{l}$. The median neonatal value in the group ( $61 \mathrm{mU} / 1$ plasma) was significantly lower than in the diagnosed group $(p<0.001)$. At the age of 5 years all nine children had serum thyrotrophin, thyroxine, and triiodothyronine concentrations within the reference ranges.

Two children had been delivered by caesarean section, one because gestation had been considered to be beyond term and the other because of a narrow pelvis in the mother. No prenatal or postnatal asphyxia was recorded. Two children were delivered before term, in the 30th (case 28) and 35th weeks (case 29). Both had appropriate weight and length for gestational age. The mean birth weight of the full term infants was $3500 \mathrm{~g}$. The male to female ratio was $3: 6$.

One preterm child (case 28) had been given phototherapy for hyperbilirubinaemia. In all other cases the neonatal periods had been uncomplicated. There was no indication of exposure to excess iodine in any of the children.

At follow up at the age of 5 years the heights of all nine euthyroid children were within 2 SD for age. Griffiths tests were administered to all but three; the mean developmental quotient was 107 and did not differ significantly from the control value. Table III gives the results of the individual scales in the Griffiths test.

Neurological development tests were performed in all but two children. Only one (case 26 ) had a one year retardation in her fine motor and visual motor performance.

\section{Discussion}

Congenital hypothyroidism signifies hypothyroidism present at birth. In practice, however, the disorder requires an operational definition. When congenital hypothyroidism is diagnosed from clinical signs and symptoms before 2 years of age the Swedish incidence is reported as one in $6900 .^{2}$ The current Swedish neonatal screening programme, however, detects 100 cases in every 287660 infants screened-that is, an incidence of one in 2900. This difference is significant $(p<0 \cdot 01)$. This increased rate of detection by screening has also been observed in other screening programmes. It indicates that congenital hypothyroidism is underdiagnosed when based on clinical signs and symptoms and overdiagnosed when detected by laboratory screening. We have tried to elucidate this problem. We have analysed thyrotrophin retrospectively in stored neonatal filter paper blood samples in order to identify infants 
with raised concentrations and examined these children at the age of 5 years.

Thyrotrophin values decay in stored filter paper blood samples. ${ }^{11}$ No increase in thyrotrophin or thyroxine has been reported in stored samples and such an event seems unlikely. The filter paper blood samples in our series had been kept at $4^{\circ} \mathrm{C}$ for four years. This has been shown to result in very little decay of thyroxine. ${ }^{6}$ The decay of thyrotrophin has been reported to be variable and temperature dependent. ${ }^{11}$ Decay of thyrotrophin has not been studied under the conditions used here but it seems reasonable to assume that some activity was lost during the four years of storage. One reason for selecting $40 \mathrm{mU}$ thyrotrophin per litre plasma, instead of the $50 \mathrm{mU} / \mathrm{l}$ that we use for routine prospective neonatal screening, was to compensate for this decay. Another was that owing to the limited amount of sample material available and also to minimise reagent costs single rather than duplicate samples were analysed. This results in higher variability than when analyses are performed in duplicate, as is done for routine prospective screening.

The specificity of the screening analysis for thyrotrophin is crucial. Falsely raised activity due to maternal antirabbit IgG has been described. ${ }^{1213}$ This source of error was eliminated in the assay that we used. In earlier work we did, however, observe some cross reactivity of the MILAB rabbit antihuman thyrotrophin with material that was not thyrotrophin. Hence it was essential to test all samples that were positive in the initial MILAB screening determination with an alternative rabbit antihuman thyrotrophin (Calbiochem). This second analysis eliminated 134 of 166 positive samples (table I). The frequency of positive screening test results was thus one in 3100 , which is virtually identical with the frequency with which patients with congenital hypothyroidism are identified by the prospective Swedish screening programme.

In our screened cohort the number of patients with congenital hypothyroidism identified from clinical symptoms during their first four years of life was 15 or one in 6700 , which is in good agreement with previous estimates. ${ }^{2}$ All 15 patients had substantially raised thyrotrophin values in their neonatal filter paper samples (table II). Though all were included in the Swedish health care programme, ${ }^{14}$ the median age at diagnosis was 5 months (range 2 weeks to $3 \frac{1}{2}$ years). They showed a range of intellectual and neurological handicaps comparable to those observed earlier in similar patients. ${ }^{15}$ Their mean global Griffiths developmental quotient was decreased to the -1.5 SD of a healthy control population (table II). There was no correlation between the reduced developmental quotient and age at start of treatment. Five out of 13 patients had abnormal gross, fine, and visual motor performance at the age of 5 years. It remains to be established whether these handicaps can be prevented by starting treatment during the first weeks of life.

Of the remaining children, seven (cases 16-22; table II) were found to be hypothyroid at the age of 5 years but had not been detected clinically. They were classified as undiagnosed. This classification rested primarily on their basal serum thyrotrophin response to stimulation by thyrotrophin releasing hormone. Evidently their thyroid insufficiency had in part been compensated by an increase in serum thyrotrophin-at least until follow up at 5 years of age. The nature of their hypothyroidism remained to be established. None had goitre. We could only speculate that these children had a hypoplastic thyroid and were constantly at risk of becoming uncompensated, and may have been so during critical periods in the development of their central nervous system. Support for this comes from their low motor and performance developmental quotients as compared with those of the euthyroid group (table III).

The nine children in the last subgroup (cases 23-31) were clinically and biochemically euthyroid at 5 years of age (table II). Most had thyrotrophin values below $100 \mathrm{mU} / 1$ in their neonatal screening samples and might have represented the tail of the normal Gaussian distribution of euthyroid infants. The usual diagnostic procedure after finding a raised thyrotrophin concentration on screening requires that the abnormal result should be verified by serum hormone analysis. Furthermore, treatment is not instituted unless the serum thyroxine value is subnormal. In this retrospective study we could not estimate how many such euthyroid children might have been excluded from the group with positive screening results by this procedure.

A low plasma thyrotrophin concentration in the neonatal period might also indicate transient congenital hypothyroidism, described originally in sick newborn infants, ${ }^{16}$ or be caused by excessive exposure to iodine. ${ }^{17}$ There was no evidence of either of these in this study.

Both the children with diagnosed congenital hypothyroidism and those with undiagnosed disease at 5 years of age scored lower than the euthyroid children in the motor and performance scales of the Griffiths test (table III). The similar pattern of developmental delay in the two groups indicated that the patients with undiagnosed disease may also have suffered from lack of thyroid hormone during critical periods of development.

Our results indicate that congenital hypothyroidism will be underdiagnosed if clinical signs and symptoms are used as indicators of thyroid hormone insufficiency. Furthermore, those patients who are diagnosed by that approach will be detected too late. Neonatal screening based on thyrotrophin analyses, on the other hand, may lead to a degree of overdiagnosis, roughly a quarter of children with raised thyrotrophin values in their neonatal filter paper blood samples having normal thyrotrophin and thyroid hormone concentrations at 5 years as well as normal intellectual and neurological development. It must be emphasised that the methods used to assess development are crude and may fail to detect disturbances in neurological development. Children who are euthyroid at follow up are most likely a heterogeneous group, and some may have more or less compensated hypothyroidism. It is not easy to identify which of those infants with true positive results in a neonatal screening programme will remain compensated in their thyroid function. The policy of thyroxine substitution for all infants with raised thyrotrophin concentrations and low normal or subnormal serum thyroxine values detected in a neonatal screening programme seems justified provided that the hormone concentrations show no tendency spontaneously to return to normal during the first few weeks of life. To identify children with transient congenital hypothyroidism it is important to test endogenous thyroid function at 1-2 years of age by withdrawing treatment for a short period and analysing serum hormone responses.

The following conclusions emerge from our study. Firstly, all children with congenital hypothyroidism who are diagnosed from clinical symptoms (that is, amounting to an incidence of one in 7000) may be detected by neonatal screening of thyrotrophin values. Secondly, without laboratory screening there may be a considerable delay in diagnosis and initiation of treatment, a delay that in about $40 \%$ of cases may exceed one year. Thirdly, neonatal screening yields an incidence of congenital hypothyroidism of about one in 3000 , and thyroxine treatment may be started at about 2 weeks of age. Fourthly, laboratory screening detects children with congenital hypothyroidism who would otherwise remain undiagnosed at the age of 5 years; these constitute about a quarter of all patients identified by screening. Lastly, laboratory screening based on plasma thyrotrophin concentrations may lead to a degree of overdiagnosis - that is, some children with raised thyrotrophin concentrations in the neonatal period may be euthyroid at the age of 5 and have no apparent sequelae. These also account for about a quarter of all patients detected by screening.

We are grateful to $S$ Pioud-Wadén for performing the Griffiths tests. This study was supported by grants from the Swedish Medical Research Council $(722,4792,4930)$, the Sävstaholmsföreningen, and the Swedish Medical Association. The study was presented in part at the Acta Endocrinologica Congress, Stockholm, on 27 June 1983, and at a meeting of the European Society for Paediatric Endocrinology, Budapest, on 31 August 1983. 


\section{References}

1 De Jonge EA. Congenital hypothyroidism in the Netherlands. Lancet 1976;ii:143. Alm J, Larsson A, Zetterström R. Congenital hypothyroidism in Sweden. Incidence and age at diagnosis. Acta Paediatr Scand 1978;67:1-3.

3 Brock-Jacobsen B, Brandt NJ. Congenital hypothyroidism in Denmark. Arch Dis Child 1981; 56 :134-6.

Delange F, Illig R, Rochiccioli P, Brock-Jacobsen B. Progress report 1980 on neonatal thyroid screening in Europe. Acta Paediatr Scand 1981;70:1-2.

5 Fisher DA Dussault J Results of screening one million North American infants. $\exists$ Pediatr $1979 ; 94$ : $700-5$.

6 Larsson A, Ljunggren JG, Lundberg K. TSH and thyroxine in stored neonatal filter paper blood samples from patients with congenital hypothyroidism. Acta Paediatr Scand 1982;71:39-41.

7 Ounsted MK, Osborn ML, Sleigh G, Good FJ. A method of developmental assessment at four years and some associated findings. Early Hum Dev 1979;3:

8 Towen CL, Prechtl HFR. The neurological examination of the child with minor nervous dysfunction. Clinics in developmental medicine. No 38. London:

9 Alin-Âkerman B, Nordberg L. Griffiths' developmental scales I and II. Manual for administration and evaluation. Stockholm: Psykologiförlaget AB, 1980.
10 Foley TP, Owings J, Hayford JT, Blizzard RM. Serum thyrotropin response to synthetic thyrotropin-releasing hormone in normal children and hypopituitary patients. F Clin Invest 1972;51:431-7.

11 Walfish PG, Gera E. Experience with the application of a dried blood thyrotropin TSH) method for neonatal hypothyroidism screening: comparative studies between antibody and solid phase radioimmunoassays. In : Bickel $\mathbf{H}$, Guthrie R, Hammersen G, eds. Neonatal

12 Hedenborg G Pettersson T, Carlström A. Heterophilic antibodies causing falsely raised thyroid-stimulating-hormone result. Lancet 1979;ii:755.

13 Larsson A, Carlström A, Hedenborg G. Placental transfer of maternal antirabbit IgG causing falsely elevated TSH levels in neonates analysed by radioimmunoassay. Acta Paediatr Scand 1981;70:699-703.

14 Sjölin S, Vahlquist B. Child health in Sweden. Acta Paediatr Scand 1974;63:

15 Alm J, Larsson A, Zetterström R. Congenital hypothyroidism in Sweden. Psychomotor development in patients detected by clinical signs and symptoms. Acta Paediatr Scand 1981;70:907-12.

16 Delange F, Dodion J, Wolter R, et al. Transient hypothyroidism in the newborn infant. F Pediatr 1978;92:974-6.

17 Chabrolle JP, Rossier A. Goitre and hypothyroidism in the newborn after cutaneous absorption of iodine. Arch Dis Child 1978;53:495-8.

(Accepted 31 August 1984)

\title{
Effect of cimetidine on upper gastrointestinal bleeding after renal transplantation: a prospective study
}

\author{
$S$ WALTER, J THORUP ANDERSEN, U CHRISTENSEN, H LØKKEGAARD, H KJERSEM, \\ J I DAHLAGER JØRGENSEN, F STADIL
}

\begin{abstract}
In 97 consecutive patients undergoing renal transplantation the incidence of upper gastrointestinal bleeding was registered over 180 days after allocation to treatment with either cimetidine or placebo. Bleeding episodes occurred in 12 patients, 11 of whom were receiving placebo and only one cimetidine $(p<0.01)$. All bleeding episodes occurred during the first month after allotransplantation. Treatment with cimetidine did not lead to an increased incidence of rejection of the allograft.

It is concluded that cimetidine is effective and safe in protecting against upper gastrointestinal bleeding after renal transplantation.
\end{abstract}

\section{Introduction}

Peptic ulceration is common in chronic renal failure. After renal transplantation the risk of upper gastrointestinal bleeding increases considerably. The incidence is $5-12 \%,{ }^{1-5}$ and because mortality in patients in whom it develops is above $50 \%$ prophylactic gastric surgery has been considered. ${ }^{1}$ The reason for the increase in bleeding episodes is uncertain. Chisholm et al found a significant increase in peak acid output in men after renal transplantation but not in women. ${ }^{4}$ The increase was not related to the steroid dose, the presence of hyperparathyroidism,

Herlev Hospital, University of Copenhagen, Herlev, Denmark

$S$ WALTER, MD, PHD, senior registrar, department of urology

U CHRISTENSEN, MD, registrar, department of nephrology

H LØKKEGAARD, MD, PHD, chief nephrologist, department of nephrology

Rigshospitalet, University of Copenhagen

J THORUP ANDERSEN, MD, PHD, senior registrar, department of surgery $\mathrm{D}$, section of urology

H KJERSEM, MD, registrar, department of nephrology

J I DAHLAGER JØRGENSEN, MD, senior registrar, department of nephrology

F STADIL, MD, PHD, professor of surgery, department of surgery C

Correspondence and requests for reprints to: Dr $S$ Walter, Department of Urology H, Herlev Hospital, DK-2730 Herlev, Denmark. or the severity of the previous uraemia. They concluded that prophylactic surgery was not indicated. Conversely, Doherty suggested that upper gastrointestinal bleeding after renal transplantation could be prevented if steroids were used more sparingly, but he gave no information on the effect on secretion of acid. ${ }^{6}$

Histamine $\mathrm{H}_{2}$ receptor antagonists are potent inhibitors of secretion of gastric acid and might prove useful in preventing upper gastrointestinal bleeding after renal transplantation. The aim of this prospective study was to assess the effects of cimetidine on upper gastrointestinal bleeding after renal transplantation and on allograft function and the incidence of rejection.

\section{Patients and methods}

Ninety seven patients consecutively admitted for renal transplantation ( 40 women, 57 men) entered the study after giving their informed consent. Ninety two of the patients were screened for gastric or duodenal ulcer before transplantation with radiological studies or gastroduodenoscopy or both: we excluded from the study patients aged under 16 , patients with acute gastroduodenal ulcer, and patients with blood or liver diseases.

Treatment with placebo or cimetidine was started immediately after the transplantation. During the postoperative intestinal paralysis the drug was given intravenously. The dose of cimetidine or placebo was adjusted to renal function as follows: creatinine clearance below $15 \mathrm{ml} / \mathrm{min}, 200 \mathrm{mg}$ twice daily; $15-40 \mathrm{ml} / \mathrm{min}, 200 \mathrm{mg}$ thrice daily; and over $40 \mathrm{ml} / \mathrm{min}, 200 \mathrm{mg}$ thrice daily and $400 \mathrm{mg}$ at bedtime. The immunosuppressive regimen was azothioprine $3 \mathrm{mg} / \mathrm{kg} / \mathrm{day}$ and prednisone $1 \mathrm{mg} / \mathrm{kg} /$ day reduced to $20 \mathrm{mg}$ daily after four weeks. The trial was designed to be continued for 180 days.

Gastrointestinal bleeding was defined as the occurrence of haematemesis or melaena, or both, with a fall in haemoglobin concentration. If gastrointestinal haemorrhage occurred the patient was withdrawn from the trial and treated with emergency operation or cimetidine.

The $\chi^{2}$ test was used for statistical analysis.

\section{Results}

Several patients dropped out before the end of the observation period, mostly because of removal of the graft, upper gastrointestinal bleeding, or death. None were withdrawn because of side effects of cimetidine. Sixty nine patients were observed for 30 days, $\mathbf{4 9}$ for $\mathbf{9 0}$ 